EXTENDED REPORT

\title{
Fibromyalgia: a randomised, controlled trial of a treatment programme based on self management
}

\author{
C Cedraschi, J Desmeules, E Rapiti, E Baumgartner, P Cohen, A Finckh, A F Allaz, T L Vischer
}

Ann Rheum Dis 2004;63:290-296. doi: 10.1136/ard.2002.004945

\begin{abstract}
See end of article for authors' affiliations

Correspondence to:

Dr C Cedraschi, Division of Rheumatology, University

Hospital, 1211 Geneva

14, Switzerland;

Christine.Cedraschi@

houge.ch
\end{abstract}

Accepted 12 May 2003

\begin{abstract}
Objective: To evaluate the efficacy of a treatment programme for patients with fibromyalgia (FM) based on self management, using pool exercises and education.

Methods: Randomised controlled trial with a 6 month follow up to evaluate an outpatient multidisciplinary programme; 164 patients with FM were allocated to an immediate 6 week programme $(n=84)$ or to a waiting list control group $(n=80)$. The main outcomes were changes in quality of life, functional consequences, patient satisfaction and pain, using a combination of patient questionnaires and clinical examinations. The questionnaires included the Fibromyalgia Impact Questionnaire (FIQ), Psychological General Well-Being (PGWB) index, regional pain score diagrams, and patient satisfaction measures.

Results: 61 participants in the treatment group and 68 controls completed the programme and 6 month follow up examinations. Six months after programme completion, significant improvements in quality of life and functional consequences of FM were seen in the treatment group as compared with the controls and as measured by scores on both the FIQ (total score $p=0.025$; fatigue $p=0.003$; depression $p=0.031$ ) and PGWB (total score $p=0.032$; anxiety $p=0.011$; vitality $p=0.013$,). All four major areas of patient satisfaction showed greater improvement in the treatment than the control groups; between-group differences were statistically significant for "control of symptoms", "psychosocial factors", and "physical therapy" No change in pain was seen.

Conclusion: A 6 week self management based programme of pool exercises and education can improve the quality of life of patients with FM and their satisfaction with treatment. These improvements are sustained for at least 6 months after programme completion.
\end{abstract}

$\mathrm{T}$ fibromyalgia (FM) syndrome is characterised by generalised musculoskeletal pain, a predictable pattern of "tender points" (TP), stiffness, fatigue, and disturbed sleep. ${ }^{1} \mathrm{FM}$ affects women about eight times more often than men. ${ }^{2}$ Emotional distress is common in $\mathrm{FM}^{3}$ and quality of life is impaired, ${ }^{45}$ often more so than in other painful diseases such as rheumatoid arthritis. ${ }^{67}$ Although there is no specific treatment, various management programmes have been proposed to deal with different aspects of the disease, particularly psychological distress, poor quality of life, functional impairments, ${ }^{8-10}$ decreased muscle strength and endurance, ${ }^{11}$ and low levels of physical fitness. ${ }^{12}$

The critical elements of successful self management programmes for FM include education about the syndrome and a well informed patient at the centre of the management team. ${ }^{13}$ Such programmes emphasise communication and a combination of cognitive-behavioural techniques and physical training such as pool exercises which, together with walking, are well tolerated by patients with FM. ${ }^{14-17}$ However, programmes emphasising exercise can have low volunteer rates, ${ }^{18}$ a high number of drop outs, ${ }^{10}$ or poor compliance due to increased pain after exercise. ${ }^{19}$ Despite the substantial economic and human costs of FM, few randomised studies have evaluated such treatment programmes. There are no published studies on multidisciplinary programmes including pool exercises and education which enrolled a large number of patients and conducted follow up over a period of at least 6 months.

This study evaluated a multidisciplinary self management programme developed in consultation with a local FM association. The programme explicitly promoted self management strategies, combining pool exercises and education. It was suggested that the programme would improve the participants' quality of life and satisfaction with treatment, as well as decrease the functional and symptomatic consequences of FM, as compared with a control group.

\section{MATERIALS AND METHODS \\ Subjects}

Participants were volunteers from among patients with FM referred to the divisions of rheumatology and re-education at the Geneva University Hospital. Participation was proposed to 176 consecutive outpatients diagnosed with FM and living in the Geneva area. Recruitment was from November 1998 to September 2000 and follow up from June 1999 to April 2001. The major inclusion criteria were the American College of Rheumatology criteria for $\mathrm{FM}^{1}$ and sufficient fluency in French to participate in group sessions. Exclusion criteria were the presence of specific medical disorders which required immediate treatment (for example, fractures, infectious diseases), prevented physical activity (for example, cardiovascular problems) or participation in swimming pool sessions (for example, skin diseases, allergy to chlorine). The protocol was approved by the local ethics committee and written informed consent was obtained from all participants.

Both the treatment and control groups were evaluated at baseline and at the 6 month follow up. The treatment group participated in a 6 week programme with re-evaluation 6 months after programme completion. The control group was offered the treatment programme after the 6 month follow up evaluation. The treatment and control groups

\footnotetext{
Abbreviations: FIQ, Fibromyalgia Impact Questionnaire; SF-36, Short Form-36; FM, fibromyalgia; PGWB, Psychological General Well-Being; RPS, regional pain score; TP, tender points
} 
continued to receive their regular care, including physical therapy, drug treatment and, in some cases, psychotherapy.

\section{Programme}

The multidisciplinary programme consisted of 12 sessions, twice a week for 6 weeks. Attendance at $\geqslant 10$ sessions was considered full compliance with the programme; $3-9$ as partial compliance, and $<3$ as withdrawal. Each session lasted 90 minutes $(2 \times 45$ minutes $)$ and was conducted in groups of $8-10$ people. The programme included swimming pool sessions in $34^{\circ} \mathrm{C}$ water $(8 \times 45$ minutes $)$, relaxation exercises $(4 \times 45$ minutes $)$, low impact land based exercises ( $2 \times 45$ minutes), sessions on activities of daily living ( $2 \times 90$ minutes), and education-discussion sessions $(6 \times 45$ minutes). Pool and land based sessions were led by a physiotherapist. Sessions on "activities of daily living" were led by an occupational therapist and examined questions on everyday life from the weekly diaries of the participants. The education-discussion sessions were held with the entire management team, including a rheumatologist and a psychologist, and dealt with many aspects of FM such as current scientific knowledge, associated conditions, symptoms, modulating factors, and personal relationships. One of these sessions offered participants the opportunity to invite a support person.

Throughout the programme, self management was explicitly promoted: participants were instructed to find their own pace when exercising and in their daily activities. The pool sessions and the land based exercises (relaxation and low impact) mainly aimed at breaking the inactivity pattern of patients with FM but also at helping them to apply relaxation techniques. The activities of daily living sessions focused on helping the participants to plan their activities in order to minimise fatigue and pain, and thus eventually to increase their level of activity. The education-discussion sessions provided further opportunities to discuss the difficulties of everyday life and share possible solutions.

\section{Patient examination}

Baseline and follow up examinations were performed by experienced rheumatologists and physiatrists, according to the protocol described by Wolfe et al. ${ }^{1}$ The number of TP and the myalgic score were recorded. Participants were interviewed by the examining physician using a standardised questionnaire to record sociodemographic characteristics, date of symptom onset, duration of symptoms, concurrent health problems, and use of healthcare services in the previous 6 months-that is, number of visits to a general practitioner, a specialist (rheumatologist or physiatrist), a psychiatrist or psychologist, and/or a physical therapist. Physical treatments included active (for example, exercises) and passive (for example, massage) modalities. The physician rated his or her clinical global impression on a five point scale $(1=$ best $)$.

\section{Self administered questionnaire}

At the time of the baseline and follow up medical evaluations subjects were asked to bring a self administered questionnaire which had been mailed to them beforehand. This questionnaire included elements from five standard instruments. Quality of life was evaluated using questions from the validated French version of the Psychological General WellBeing (PGWB) index ${ }^{20-22}$ and the validated French version of the Short Form-36 (SF-36), ${ }^{23}$ a non-specific health and functional status questionnaire. The PGWB instrument has six subscales for a total of 22 items measuring "anxiety", "depression", "general health", "positive wellbeing", "self control", and "vitality". Each item is scored from 0 to 5, providing a total score of between 0 and 110, with higher values indicating more positive responses. The SF-36 subscales for "general health", "physical functioning", "rolephysical", and "social functioning" were used. Scores for each subscale range from 0 to 100 (best). The "roleemotional", "mental health", and "vitality" subscales were not included because of the overlap with the PGWB.

To evaluate the functional and symptomatic consequences of FM the questionnaire included elements of the Fibromyalgia Impact Questionnaire (FIQ), ${ }^{24}$ which has 10 subscales to assess "physical function", "number of days feeling bad", "work missed", "job ability", "pain", "fatigue", "morning tiredness", "stiffness", "anxiety", and "depression". Higher scores indicate a negative impact. To assess pain, the regional pain score (RPS) was included, with participants asked to indicate on a body drawing their level of pain in each of 21 regions (range: $0=$ "no pain" to $5=$ "unbearable pain"), providing a total score of between 0 and 105. The RPS has been validated with patients with FM. ${ }^{25} 26$ Patient satisfaction with the intervention was investigated using items generated by Potts and Silverman. ${ }^{27}$ Patients were asked to rate on Likert-type scales the importance and satisfaction with FM treatment in four major areas: physical therapy, symptom control, psychosocial factors, and information. For each item, response options ranged from 0 to 5 , with a higher value indicating a more positive response. At the time of the follow up evaluation, to appraise the adherence to the emphasis put on breaking the inactivity pattern during the programme, participants were asked whether they had continued swimming pool exercises regularly, had resumed an activity they had given up because of their symptoms, or engaged in a new activity.

\section{Power calculations}

Based on compliance data from a trial conducted in Geneva on electroacupuncture and $\mathrm{FM}_{1}{ }^{21}$ and attrition rates in similar studies, it was calculated that two groups of 84 patients (treatment $v$ control patients) at baseline were needed to maintain a statistical power of $80 \%(\alpha=5 \%$ and $\beta=20 \%)$ to detect a between-group difference of half a standard deviation on any continuous variable.

\section{Randomisation}

After baseline medical evaluation, participants were randomly allocated to a treatment group or a control group. The assignment was performed in blocks of 20, split into treatment programme $(n=10)$ or control $(n=10)$. Randomisation was made by means of an electronic numbers generator (SPSS). An independent person who was not responsible for determining the participants eligibility provided sequentially numbered, sealed, and opaque envelopes.

\section{Statistical methods}

Demographic data were compared using $\chi^{2}$ tests for categorical data and a $t$ test for continuous data. Study outcomes (difference scores of baseline value minus follow up value) were evaluated using the non-parametric Wilcoxon signed rank test (two tailed) for paired data. Differences between the treatment and the control groups were evaluated using the Mann-Whitney test.

\section{RESULTS}

Of the 176 consecutive patients who volunteered to participate in this study, eight were excluded for medical reasons (cardiovascular problems or allergy to chlorine) and four withdrew because of other commitments. After medical evaluation, 164 participants were randomly allocated to the treatment $(n=84)$ or the control group $(n=80)$. Sixty one patients $(73 \%)$ in the treatment group and $68(85 \%)$ in the control group completed the 6 month follow up and were 


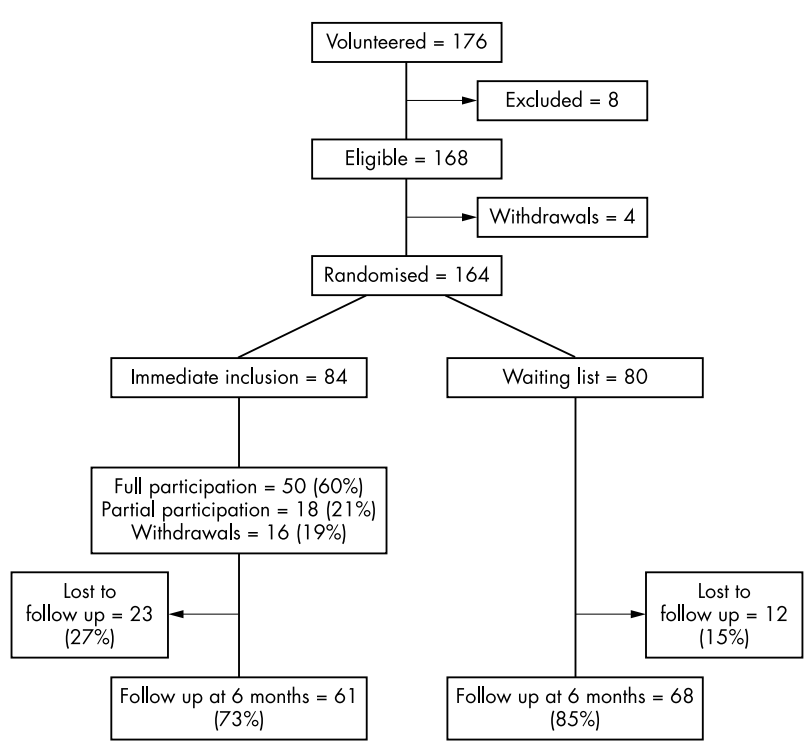

Figure 1 Flow diagram of the participants in the randomised trial.

included in the final analyses. Two participants in the treatment group explicitly cited an increase in pain as the reason for dropping out. Figure 1 presents the flow diagram of the trial. This figure also shows that full participation was obtained in $60 \%$ of the patients. The chart of attendance showed no specific bias against any particular session.

Comparison of the sociodemographic variables and duration of FM symptoms showed no statistically significant

Table 1 Sociodemographic characteristics of patients with FM by treatment group

\begin{tabular}{|c|c|c|c|}
\hline Characteristics & $\begin{array}{l}\text { Treatment } \\
\text { No (\%) }\end{array}$ & $\begin{array}{l}\text { Control } \\
\text { No (\%) }\end{array}$ & $\mathbf{p}$ \\
\hline \multicolumn{4}{|l|}{ Sex } \\
\hline Male & $6(7)$ & $6(8)$ & \multirow[t]{2}{*}{ NS } \\
\hline Female & $78(93)$ & $74(93)$ & \\
\hline \multicolumn{4}{|l|}{ Age (years) } \\
\hline$\leqslant 40$ & $20(24)$ & $16(20)$ & \multirow[t]{4}{*}{ NS } \\
\hline $41-50$ & $32(38)$ & 31 (39) & \\
\hline $51-60$ & $23(27)$ & $20(25)$ & \\
\hline$>60$ & $9(10.7)$ & $13(16)$ & \\
\hline Mean (SD) & $48.9(9.7)$ & $49.8(9.8)$ & NS \\
\hline \multicolumn{4}{|l|}{ Cultural origin } \\
\hline Switzerland & $33(39)$ & $27(34)$ & \multirow[t]{6}{*}{ NS } \\
\hline France & $6(7)$ & $7(9)$ & \\
\hline Italy & $4(5)$ & $10(13)$ & \\
\hline Spain & $8(10)$ & $7(9)$ & \\
\hline Portugal & $19(23)$ & $13(16)$ & \\
\hline Other & $14(17)$ & $16(20)$ & \\
\hline \multicolumn{4}{|l|}{ Marital status } \\
\hline Single & $6(7)$ & $5(6)$ & \multirow[t]{4}{*}{ NS } \\
\hline Married & $58(69)$ & $48(60)$ & \\
\hline Divorced & $16(19)$ & $25(31)$ & \\
\hline Widow & $4(5)$ & $2(3)$ & \\
\hline \multicolumn{4}{|l|}{ Education (completed) } \\
\hline Compulsory school & $39(46)$ & $37(46)$ & \multirow[t]{3}{*}{ NS } \\
\hline Diploma & $39(46)$ & 35 (44) & \\
\hline University degree & $6(7)$ & $8(10)$ & \\
\hline \multicolumn{4}{|l|}{ Employment status } \\
\hline Employed & $14(17)$ & $13(16)$ & \multirow[t]{4}{*}{ NS } \\
\hline Not working/retired & $12(14)$ & $20(25)$ & \\
\hline Sick leave & $19(23)$ & $15(19)$ & \\
\hline Disability pension & $39(46)$ & $32(40)$ & \\
\hline \multicolumn{4}{|c|}{ Duration of symptoms (years) } \\
\hline Mean (SD) & $8.4(8.2)$ & $9.5(9.6)$ & NS \\
\hline Total & 84 & 80 & \\
\hline
\end{tabular}

differences between the treatment and control groups (table 1). The majority of the participants in both groups were female (93\%). The mean (SD) age was 48.9 (9.7) and 49.8 (9.8) years in the treatment and control groups, respectively. Most of the patients were married (65\%), 46\% had completed compulsory school, and $37 \%$ were Swiss. Seventeen per cent of patients in the treatment group and $16 \%$ of controls were working while $43 \%$ were receiving a disability pension. The mean duration of symptoms was 8.4 years (median 5.7) in the treatment group and 9.5 years (median 6.1) in the control group. There were no differences in the use of medical, physical, or psychological treatments at baseline between the treatment and control groups. No differences were seen in sociodemographic characteristics or in any of the investigated dimensions at baseline between the subjects lost to follow up and those who completed the follow up examination in either group.

Table 2 compares the "quality of life" measurements at baseline and follow up, as reflected in the scores of the PGWB and the SF-36 items in the self administered questionnaire. The treatment group showed a significant improvement in the PGWB "anxiety" $(p=0.021)$, "vitality" $(p=0.013)$, and total scores $(p=0.016)$. The treatment group also showed improvement in each of the other PGWB scores and in all of the SF-36 scores, though these results were not statistically significant. No significant differences were seen in the baseline and follow up values in the control group; however, four of the six PGWB scores and two of the four SF-36 scores remained the same or deteriorated. In the between-group analysis the treatment group showed a significant improvement in the PGWB "anxiety" $(p=0.011)$, "vitality" $(p=0.013)$, and total scores $(p=0.032)$.

Table 3 compares the functional and symptomatic consequences of FM at baseline and the 6 month follow up as measured by the number of TP, the physician's clinical rating, the RPS, and the FIQ scores within and between the treatment and control groups. In the treatment group significant improvements were seen in the FIQ total score $(p<0.001)$, and the subscales for "fatigue" $(p=0.001)$, "morning tiredness" $(p=0.006)$ and "anxiety" $(p=0.002)$. No improvements were seen in the control group, and in that group the FIQ subscale for "pain" showed a significant deterioration $(p=0.017)$. No changes were seen in the number of TP, the myalgic score, and the RPS in either group. No change was seen in the physician's clinical rating in the treatment group, but this rating showed a significant deterioration in the control group $(p<0.05)$. A comparison of the groups showed significant improvements in the treatment group compared with the control group in the FIQ total score $(p=0.025)$ and the subscales for "pain" $(p=0.025)$, "fatigue" $(p=0.003)$, and "depression" $(p=0.031)$. Although there were no between-group differences in the use of medical and psychological services at the 6 month follow up, the treatment group used significantly less $(p=0.038)$ physical therapy services: the mean (SD) number of physical therapy visits dropped from 15.1 (15) to 7.6 (11), $(\mathrm{p}<0.05)$ in the treatment group, whereas it decreased only from 12.1 (11.9) to 10.4 (14.9) in the control group.

Table 4 shows the status of participant satisfaction in the programme. All four major areas of patient satisfaction showed greater improvement in the treatment than in the control groups; between-group differences were statistically significant for "physical therapy", "symptom control", and "psychosocial factors". The treatment group showed a significant improvement in all four of the measurements in the area of "physical therapy" (increased ability to do activities $p=0.017$, exercise instruction $p=0.011$, instruction in relaxation $p=0.000$, encouragement to practice self care $\mathrm{p}=0.030$ ). Similarly, the treatment group had a greater 
Table 2 Comparison of baseline and 6 month results of quality of life questionnaires by treatment group

\begin{tabular}{|c|c|c|c|c|c|c|c|c|c|c|c|c|c|c|}
\hline \multirow[b]{3}{*}{ Questionnaire } & \multicolumn{6}{|c|}{ Treatment } & \multicolumn{6}{|c|}{ Control } & \multirow{2}{*}{\multicolumn{2}{|c|}{$\begin{array}{l}\text { Difference between } \\
\text { groups }\end{array}$}} \\
\hline & \multicolumn{2}{|c|}{ Baseline } & \multicolumn{2}{|c|}{6 Months after } & \multicolumn{2}{|c|}{ Difference } & \multicolumn{2}{|c|}{ Baseline } & \multicolumn{2}{|c|}{6 Months after } & \multicolumn{2}{|c|}{ Difference } & & \\
\hline & Mean & (SD) & Mean & (SD) & Mean & (SD) & Mean & (SD) & Mean & (SD) & Mean & (SD) & Mean & $p$ \\
\hline \multicolumn{15}{|l|}{$P G W B+$} \\
\hline Total score $(0-110)$ & 45.9 & $(17.6)$ & 51.1 & (19.4) & $-5.2^{*}$ & (14.1) & 44.0 & (19.3) & 43.8 & (20.9) & 0.2 & $(11.6)$ & -5.4 & 0.032 \\
\hline Anxiety & 11.4 & (5.3) & 13.0 & (6.2) & $-1.6^{*}$ & (5.1) & 10.8 & (5.4) & 10.3 & $(5.6)$ & 0.5 & (4.2) & -2.1 & 0.011 \\
\hline Depression & 8.3 & (3.4) & 9.0 & $(3.6)$ & -0.7 & (3.1) & 7.6 & $(4.0)$ & 7.7 & $(4.2)$ & -0.1 & (3.0) & -0.6 & 0.126 \\
\hline General health & 5.3 & $(1.9)$ & 5.8 & $(2.1)$ & -0.5 & $(2.2)$ & 5.0 & (2.3) & 5.4 & (2.3) & -0.4 & (1.6) & -0.1 & 0.849 \\
\hline Positive wellbeing & 8.0 & (4.1) & 8.9 & (4.3) & -0.9 & $(3.0)$ & 7.5 & $(4.0)$ & 7.5 & $(4.6)$ & 0.0 & $(2.9)$ & -0.9 & 0.129 \\
\hline Self control & 6.9 & (3.4) & 7.4 & (3.3) & -0.5 & (2.9) & 6.4 & (3.4) & 6.4 & (3.3) & 0.0 & (2.6) & -0.5 & 0.298 \\
\hline Vitality & 6.0 & (3.7) & 6.9 & (3.3) & $-0.9^{*}$ & $(2.4)$ & 6.7 & $(3.4)$ & 6.5 & (3.7) & 0.2 & $(2.4)$ & -1.1 & 0.013 \\
\hline \multicolumn{15}{|l|}{$S F-36 \dagger$} \\
\hline Physical functioning & 41.8 & (18.1) & 42.2 & (19.8) & -0.4 & (15.8) & 46.8 & (19.4) & 43.9 & $(19.6)$ & 2.9 & (17.0) & -3.3 & 0.293 \\
\hline Role-physical & 14.6 & (27.3) & 21.5 & $(29.0)$ & -6.9 & (36.5) & 13.6 & (27.5) & 16.5 & (30.1) & -2.9 & $(25.7)$ & -3.9 & 0.093 \\
\hline General health & 32.6 & (16.5) & 34.3 & (17.3) & -1.7 & (11.0) & 29.8 & (18.5) & 28.8 & (18.9) & 1.0 & (13.3) & -2.7 & 0.241 \\
\hline Social functioning & 35.3 & $(21.6)$ & 41.2 & $(21.6)$ & -5.9 & (22.4) & 32.5 & (20.3) & 34.2 & (21.0) & -1.7 & (19.1) & -4.2 & 0.238 \\
\hline
\end{tabular}

improvement than the control group in the four measures of satisfaction with "symptom control", with the betweengroup improvement being significant for pain relief $(p=0.01)$ and reduced stiffness $(p=0.003)$. The treatment group also recorded a greater improvement than the controls in eight of the nine participant satisfaction measures in the areas of "psychosocial factors" and "information". Three of these improvements were significant-namely, stress reduction $(p=0.000)$, improved memory and attention $(p=0.004)$, and information on cause of condition $(p=0.007)$.

To evaluate the potential impact of the participants who had been lost to follow up, the analyses were repeated using all participants and assigning no change to the baseline and follow up values attributed to those who had been lost from either the treatment or the control groups. The statistically significant between-group differences were maintained for all scores except the PGWB total score.

At the time of the follow up evaluation, 41/61 (67\%) patients in the treatment group were continuing swimming pool exercises regularly. Resuming an activity given up because of the symptoms was mentioned in $23 \%$ of the patients in the treatment group $v 9 \%$ in the control group $(\mathrm{p}=0.058)$, and engaging in a new activity in $25 \% \vee 9 \%$ $(\mathrm{p}=0.028)$.

\section{DISCUSSION}

This study found that patients with FM enrolled in a 6 week self management based programme which included warm water activities and education had significant improvements in both quality of life and the functional consequences of FM as compared with a control group. The treatment group also showed significant improvements in patient satisfaction, particularly when compared with the controls. These improvements were sustained 6 months after completion of the programme. Though similar self management programmes have for some time been promoted as an important part of FM treatment, this randomised control study reports the results of a programme combining warm water activities and education with sufficient patient numbers and follow up to have the power to begin critically evaluating these treatments.

Table 3 Comparison of baseline and 6 month results of symptomatic and functional consequences of FM by treatment group

\begin{tabular}{|c|c|c|c|c|c|c|c|c|c|c|c|c|c|c|}
\hline \multirow[b]{3}{*}{ Consequences } & \multicolumn{6}{|c|}{ Treatment } & \multicolumn{6}{|c|}{ Control } & \multirow{2}{*}{\multicolumn{2}{|c|}{$\begin{array}{l}\text { Difference } \\
\text { between groups }\end{array}$}} \\
\hline & \multicolumn{2}{|c|}{ Baseline } & \multicolumn{2}{|c|}{6 Months after } & \multicolumn{2}{|c|}{ Difference } & \multicolumn{2}{|c|}{ Baseline } & \multicolumn{2}{|c|}{6 Months after } & \multicolumn{2}{|c|}{ Difference } & & \\
\hline & Mean & (SD) & Mean & (SD) & Mean & (SD) & Mean & (SD) & Mean & (SD) & Mean & (SD) & Mean & $\mathbf{p}$ \\
\hline \multicolumn{15}{|l|}{ Physician's evaluation of pain } \\
\hline Tender points $(\mathrm{n})$ & 15.4 & (2.3) & 15.0 & (3.6) & 0.4 & (3.1) & 15.8 & (2.8) & 16.2 & (2.7) & -0.4 & (2.3) & 0.8 & 0.216 \\
\hline Tender points $>1$ (n) & 10.5 & (4.8) & 9.9 & (4.9) & 0.6 & $(4.0)$ & 10.9 & (4.4) & 11.4 & (4.8) & -0.5 & $(5.2)$ & 0.1 & 0.282 \\
\hline Myalgic score & 29.9 & (9.1) & 29.5 & (11.5) & 0.4 & (8.0) & 30.6 & (9.1) & 31.8 & $(10.2)$ & -1.2 & $(9.2)$ & 1.5 & 0.461 \\
\hline Physician's score $†$ & 2.8 & (1.0) & 2.8 & (1.0) & 0.0 & (1.3) & 2.8 & (1.0) & 3.1 & $(0.8)$ & $-0.3^{*}$ & (0.8) & 0.4 & 0.052 \\
\hline Regional pain score $\neq(0-105)$ & 63.9 & $(18.0)$ & 62.6 & $(20.7)$ & 1.3 & (14.2) & 67.0 & (15.7) & 68.4 & $(15.1)$ & -1.4 & (11.6) & 2.7 & 0.391 \\
\hline \multicolumn{15}{|c|}{ Functional and symptomatic consequences of FM (FIQ $\neq)$} \\
\hline Total score & 5.5 & (1.3) & 4.9 & $(1.4)$ & $0.6^{* * *}$ & $(1.2)$ & 5.6 & $(1.6)$ & 5.5 & $(1.5)$ & 0.1 & $(1.2)$ & 0.7 & 0.025 \\
\hline Physical function & 4.2 & (2.0) & 4.3 & (2.1) & -0.1 & (1.8) & 4.5 & $(2.2)$ & 4.8 & $(2.5)$ & -0.3 & (1.8) & 0.2 & 0.584 \\
\hline Feel bad & 8.3 & (2.3) & 8.2 & $(2.6)$ & 0.1 & (3.3) & 8.0 & (2.8) & 7.9 & $(2.5)$ & 0.1 & $(2.6)$ & 0.0 & 0.697 \\
\hline Work missed & 1.6 & (4.1) & 3.3 & (2.7) & -1.7 & $(4.6)$ & 2.5 & (3.9) & 3.1 & (4.7) & -0.6 & (5.5) & -1.1 & 0.713 \\
\hline Job ability & 6.1 & (2.5) & 4.7 & (2.5) & 1.4 & $(2.4)$ & 6.7 & (2.5) & 4.7 & (3.5) & 2.0 & (3.2) & -0.6 & 0.897 \\
\hline Pain & 6.3 & (1.9) & 6.1 & (2.1) & 0.2 & (2.0) & 6.0 & (2.1) & 6.6 & $(2.1)$ & $-0.6^{*}$ & (2.2) & 0.8 & 0.025 \\
\hline Fatigue & 7.5 & (1.7) & 6.5 & (2.3) & $1.0^{* *}$ & $(2.2)$ & 7.4 & (2.4) & 7.7 & (1.9) & -0.3 & (2.3) & 1.3 & 0.003 \\
\hline Morning tiredness & 7.7 & (2.0) & 6.8 & (2.3) & $0.9^{* *}$ & $(2.2)$ & 7.6 & (2.5) & 7.5 & $(2.2)$ & 0.1 & $(2.1)$ & 0.8 & 0.056 \\
\hline Stiffness & 6.6 & (2.7) & 6.3 & (2.0) & 0.3 & $(2.2)$ & 6.5 & (2.7) & 6.8 & $(2.6)$ & -0.3 & $(2.6)$ & 0.6 & 0.147 \\
\hline Anxiety & 6.4 & (2.6) & 5.1 & (2.9) & $1.3^{* \star}$ & (3.1) & 7.1 & (2.7) & 6.7 & $(3.0)$ & 0.4 & $(2.0)$ & 0.9 & 0.078 \\
\hline Depression & 5.5 & (3.1) & 4.6 & (3.1) & 0.9 & (2.9) & 5.9 & (3.5) & 6.1 & (3.4) & -0.2 & $(2.5)$ & 1.1 & 0.031 \\
\hline
\end{tabular}


Table 4 Comparison of baseline and 6 month results of patient's satisfaction questionnaire by treatment group

\begin{tabular}{|c|c|c|c|c|c|c|c|c|c|c|c|c|c|c|}
\hline \multirow[b]{3}{*}{ Results } & \multicolumn{6}{|c|}{ Treatment } & \multicolumn{6}{|c|}{ Control } & \multirow{2}{*}{\multicolumn{2}{|c|}{$\begin{array}{l}\text { Difference } \\
\text { between } \\
\text { groups }\end{array}$}} \\
\hline & \multicolumn{2}{|c|}{ Baseline } & \multicolumn{2}{|c|}{6 Months after } & \multicolumn{2}{|l|}{ Difference } & \multicolumn{2}{|c|}{ Baseline } & \multicolumn{2}{|c|}{6 Months after } & \multicolumn{2}{|c|}{ Difference } & & \\
\hline & Mean & (SD) & Mean & (SD) & Mean & (SD) & Mean & (SD) & Mean & (SD) & Mean & (SD) & Mean & p \\
\hline Control of symptoms & 7.8 & (3.9) & 10.2 & (5.2) & $-2.4^{*}$ & $(5.4)$ & 7.1 & (4.5) & 7.3 & $(4.8)$ & -0.2 & $(4.0)$ & -2.2 & 0.007 \\
\hline Pain relief & 2.0 & (1.1) & 2.7 & (1.5) & $-0.7^{*}$ & (1.5) & 1.8 & (1.3) & 1.9 & (1.4) & -0.1 & $(1.2)$ & -0.6 & 0.010 \\
\hline Reduced fatigue & 1.9 & (1.3) & 2.4 & (1.4) & $-0.5^{*}$ & (1.7) & 1.5 & (1.4) & 1.6 & (1.4) & -0.1 & (1.4) & -0.4 & 0.195 \\
\hline Improved sleep & 2.2 & (1.4) & 2.6 & (1.3) & -0.4 & (1.7) & 2.1 & (1.3) & 2.1 & (1.5) & 0.0 & (1.3) & -0.4 & 0.182 \\
\hline Reduced stiffness & 1.6 & (1.3) & 2.5 & (1.5) & $-0.9^{*}$ & $(1.8)$ & 1.7 & (1.4) & 1.7 & (1.3) & 0.0 & (1.3) & -0.9 & 0.003 \\
\hline Psychosocial factors & 9.9 & $(5.0)$ & 14.7 & $(5.3)$ & $-4.8^{* *}$ & $(5.9)$ & 10.1 & $(5.2)$ & 11.3 & $(5.7)$ & -1.2 & $(5.3)$ & -3.6 & 0.005 \\
\hline Discussion of ways to reduce stress & 2.1 & (1.4) & 3.3 & (1.1) & $-1.2^{* *}$ & $(1.4)$ & 2.2 & (1.4) & 2.2 & (1.5) & 0.0 & (1.3) & -1.2 & 0.000 \\
\hline Reduced depression & 2.5 & (1.4) & 2.9 & (1.3) & -0.4 & (1.6) & 2.6 & (1.3) & 2.4 & (1.7) & 0.2 & $(1.6)$ & -0.6 & 0.065 \\
\hline Reduced anxiety & 2.3 & (1.5) & 2.9 & $(1.2)$ & $-0.6^{*}$ & (1.5) & 2.1 & (1.5) & 2.4 & (1.5) & -0.3 & (1.5) & -0.3 & 0.265 \\
\hline Improved memory and attention & 1.2 & (1.3) & 2.5 & (1.4) & $-1.3^{* *}$ & (1.7) & 1.5 & (1.5) & 1.9 & (1.5) & $-0.4^{*}$ & (1.5) & -0.9 & 0.004 \\
\hline Inclusion of family in physician visits & 2.3 & (1.7) & 3.4 & $(1.4)$ & $-1.1^{* *}$ & (1.9) & 1.9 & (1.7) & 2.8 & $(1.6)$ & $-0.9^{*}$ & $(2.0)$ & -0.2 & 0.407 \\
\hline Information & 10.4 & $(4.0)$ & 12.1 & (4.2) & $-1.7^{*}$ & $(4.7)$ & 9.7 & $(4.4)$ & 10.2 & $(4.9)$ & -0.5 & (4.5) & -1.2 & 0.129 \\
\hline On prognosis & 2.7 & (1.3) & 3.3 & (1.3) & $-0.7^{*}$ & (1.6) & 2.3 & (1.5) & 2.6 & (1.5) & -0.3 & $(1.6)$ & -0.4 & 0.279 \\
\hline On cause of condition & 2.8 & (1.3) & 3.6 & (1.2) & $-0.8^{*}$ & (1.6) & 2.7 & (1.5) & 2.8 & (1.5) & -0.1 & $(1.6)$ & -0.7 & 0.007 \\
\hline On diagnostic techniques & 2.2 & (1.4) & 2.6 & (1.3) & -0.4 & (1.6) & 2.1 & (1.6) & 2.2 & $(1.6)$ & -0.1 & (1.6) & -0.3 & 0.317 \\
\hline On drug side effects & 2.7 & $(1.3)$ & 2.6 & $(1.4)$ & 0.1 & (1.9) & 2.5 & $(1.5)$ & 2.6 & $(1.6)$ & -0.1 & (1.7) & 0.2 & 0.647 \\
\hline Physical therapy & 8.4 & (4.1) & 12.7 & $(4.6)$ & $-4.3^{\star *}$ & 4.9 & 8.6 & $(4.2)$ & 9.2 & $(4.9)$ & -0.6 & $(4.7)$ & -3.7 & 0.000 \\
\hline Increased ability to do activities & 1.8 & $(1.2)$ & 2.8 & (1.4) & $-1.0^{* *}$ & $(1.5)$ & 1.9 & (1.5) & 2.1 & (1.4) & -0.2 & (1.7) & -0.8 & 0.017 \\
\hline Exercise instruction & 2.3 & $(1.6)$ & 3.3 & (1.4) & $-1.0^{*}$ & $(2.1)$ & 1.9 & (1.5) & 2.1 & (1.6) & -0.2 & $(1.6)$ & -0.7 & 0.011 \\
\hline Instruction in relaxation & 1.8 & $(1.6)$ & 3.3 & (1.3) & $-1.5^{\star \star}$ & $(1.8)$ & 2.1 & (1.4) & 2.3 & (1.5) & -0.2 & (1.4) & -1.3 & 0.000 \\
\hline Encouragement to practice self care & 2.6 & (1.3) & 3.4 & (1.4) & $-0.8^{*}$ & $(1.6)$ & 2.6 & (1.5) & 2.7 & (1.5) & -0.1 & (1.7) & -0.7 & 0.030 \\
\hline Total score & 36.8 & (12.5) & 49.5 & (17.8) & $-12.7^{\star \star *}$ & $(16.6)$ & 35.2 & (14.5) & 36.9 & (17.5) & -1.7 & (13.8) & -11.0 & 0.000 \\
\hline
\end{tabular}

Although a number of other studies have recently shown an immediate benefit from FM management programmes that included warm water activities, ${ }^{28-31}$ only two included a follow up evaluation, and only one had a no-intervention control group. In the latter, which allocated 48 patients to either 10 days of balneotherapy or a control group, Buskila et al showed a sustained benefit at 3 months for self assessed pain, fatigue, stiffness, and anxiety. ${ }^{30}$ In the other study, which randomly allocated 34 patients to a pool or land based 20 week exercise programme, Jentoft et al found a benefit at 6 months in walking time and self assessed fatigue and stiffness in both groups. ${ }^{31}$ The pool based group also showed improvements in self assessed pain, anxiety, and depression. The sex, age, ${ }^{162829}$ and symptom duration ${ }^{2930}$ of the participants in these studies were comparable to those of the patients evaluated here, though it is difficult to compare employment status owing to differences in coding for this variable.

The nature, direction, and magnitude of the findings of this study are consistent with the design of this self management programme, its various elements, and scientific publications on the treatment of patients with FM. For example, the improvements that were seen in quality of life are consistent with the development of better coping skills through this treatment programme. Throughout the programme, participants were instructed to find their own pace, when exercising and in their daily activities, with the explicit aim of promoting self management. That the treatment group also experienced substantially less fatigue and morning tiredness at 6 months is in keeping with the aims of the sessions on "activities of daily living" and physical training, as these had been specifically designed to deal with these problems. The pool sessions had been developed to break the characteristic inactivity pattern of patients with FM, whereas the activities of daily living sessions provided insight into the planning of such activities and the consequences of this planning. The improvements in the "anxiety", "vitality", and "depression" subscales of the FIQ and PGWB may demonstrate the value of providing sufficient opportunity for patients with FM to discuss the difficulties of their everyday life with other patients and various health professionals. Finally, the fact that the treatment group consistently reported greater satisfaction with their therapy than the control group reaffirms the value and potential impact of multidisciplinary management programmes that bring a range of expertise and individual attention to the challenges and problems these people experience, while doing so in a group setting that promotes their continued participation and interest.

Though the findings of this study offer encouragement in the management of patients with FM, the limitations of its design and outcomes should be recognised. Most notable is the common challenge of maintaining "blinding" in any behavioural and physical intervention study, ${ }^{29} 32$ often because of the enthusiasm of participants to disclose their experience to examiners. In this study, coding of the baseline and follow up self administered questionnaires was blinded, however, as was the baseline medical evaluation conducted before randomisation. Nevertheless, it was not possible to ensure that the follow up medical evaluation at 6 months was blind. Compliance with the intervention was defined as "attending the sessions"; considering the aim of the intervention-that is, to increase self management, actual compliance would be best evaluated as "applying the instructions at the end of the study period". However, the design of this study did not allow for a valid assessment of these aspects of compliance. Although there was some loss of follow up, the study completion rate of $79 \%$ was still high and the same as that seen in a 3 week trial on electroacupuncture and $\mathrm{FM}^{21}$ that was conducted in the same rheumatology unit. The higher drop out rate among the treatment group than controls $(27 \% v 15 \%)$ may thus have resulted from a number of factors other than chance, including a failure of the programme to meet early expectations and/or increased pain. 
These results also indicate that even though the local FM association was interested in this programme and was involved in the preliminary discussions, there may be a substantial difference between meeting a group's request and meeting individual expectations. The lack of information on the end points for the drop outs did not allow us to perform the classic intention to treat analysis. The continuous nature of the variables makes it difficult to assign a quantitative value to the missing data. For this reason we analysed the data using an approach close to the per-protocol analysisthat is, using only the cases for which there was information at the end of the follow up. This approach may have led to an overestimate of the effects of the treatment, as the patients who completed the follow up may be those who presented the best response. However, when conservatively assuming zero changes to all the drop outs, we obtained the same results, only decreasing statistical power.

A major problem in multidisciplinary interventions is that classical outcome measures may underestimate the benefits of the intervention. Using individual defined aims has been suggested as a more sensitive tool for evaluating the effectiveness of an intervention. ${ }^{33}$ This has been demonstrated in rheumatoid arthritis using the McMaster Toronto Arthritis patient preference questionnaire (MACTAR)..$^{34}$ Such instruments should be tested with patients with FM as a means to gain further insight into patients' needs and expectations. Investigating these aspects may perhaps also explain the apparent discrepancies in the results-for example, the good effect on function in the satisfaction questionnaire compared with the absence of effect on physical function in SF-36 and FIQ, which show that satisfaction may not be automatically linked to actual performance. Patients' expectations and perception of their condition and its treatment may also affect their adherence to attendance at meetings and the withdrawal rate. These expectations and beliefs are related to the patients' understanding and experience of FM, and to the cost-benefit analysis that they may do when they are prescribed a treatment. $^{527}$ One of the difficulties in obtaining patients' adherence may be a level of expectations which can hardly be matched-in a condition for which there is at present no specific treatment-and thus causes a possibly important imbalance in the cost-benefit analysis. Finally, although the French version of most of the instruments used to measure the chosen outcomes had been validated in an FM population, the questions used to measure patient satisfaction had not yet undergone such validation.

There are also some limitations to the expected impact and generalisability of this programme to other patients with FM. Although there were substantial improvements in most measures of quality of life, functional consequences of FM, and patient satisfaction with treatment, many of the follow up scores were still low compared with non-FM populations. For example, the PGWB total score in the general population is as high as $105,{ }^{36}$ whereas it reached only 51.1 in this treatment group. Similarly, the SF-36 scores studied, which are expected to range from 71 to $84^{*}$, ranged from 21.5 to 42.2 at follow up in the treatment group. Although these values are comparable to those in other FM studies, 222629 they underline the emotional distress, functional impairments, and poor quality of life that patients with FM experience. ${ }^{37}{ }^{38}$ In this regard, it would have been of interest to compare the "vitality" subscales of the PGWB and of the SF-36, as this subscale yielded significant differences before

*Richard JL, Bouzourène $K$, Gallant $S$, Ricciardi $P$, Sudre $P$, Iten $A$, Burnand B. Validation et normes du SF-36 dans la population du canton de Vaud. Lausanne: Institut universitaire de médecine sociale et préventive, 2000. and after treatment and between-group differences. However, the overlap of both questionnaires was a matter of concern, especially for the psychological dimensions; when dealing with a group with specific chronic pain addressing psychological aspects is often perceived as a possible delegitimisation of their pain and suffering and/or as a denial of the somatic aspects of their complaint. The mean duration of symptoms in our group was high and this may account for the relatively small treatment effects 6 months after the programme. Such a programme may be more successful at the beginning of the symptoms; however, there were not enough patients with early FM to carry out post hoc subgroup analysis. Also, this study did not find substantial improvement in pain, whether self assessed or in the medical evaluation. Although the comparison of the FIQ subscale for pain showed a statistically significant difference in favour of the treatment group, this difference was largely due to a deterioration in the control group. Possibly, however, the intervention prevented an increase in pain in the treatment group. An alternative explanation might be that being randomised in a waiting list group may cause disappointment and a possible worsening of pain. This observation raises the question of the patients' expectations and of the difficulties in circumventing the possible drawbacks of using a waiting list as a control group. A study on the association of patients' expectations from a specific treatment with improved functional outcome showed that patients' expectations may influence clinical outcome independently of the treatment itself. ${ }^{39}$ Using a waiting list avoids the effects of randomisation into a group that does not correspond with the patient's expectations but does not avoid the effects of having to wait for a treatment that may be helpful. Another limitation is that like other FM programmes that are based on self management, the addition of multiple interventions ${ }^{13}$ to pool activities makes it difficult to evaluate the contribution of each element. Yet, no single treatment has been shown to have more than a limited benefit in patients with FM, in part because no single causative factor has been identified..$^{32}$ Finally, although this trial was conducted in a university setting which enabled the study, the outpatient programme itself did not require this type of setting.

Despite the limitations of this study it demonstrates that sufficient numbers of patients with FM can be enrolled in randomised control trials of treatment programmes that include complex behavioural and physical interventions. Given the substantial economic and human costs of this disease, as well as the increasing incidence and/or recognition of this condition in many areas, such studies are increasingly important. Future studies should not only enrol enough patients to ensure sufficient power of the findings but also consider the need to extend the follow up period for such studies to include at least a full 12 month period. The design, logistics, and funding of such work will itself be a challenge.

\section{CONCLUSIONS}

This study reports a large randomised controlled trial, with a 6 month follow up, of a multidisciplinary self management based programme for patients with FM. It found that a 6 week treatment programme, which combined physical activity, education, promotion of self management strategies, and development of coping skills, resulted in statistically significant improvement in quality of life, functional consequences of FM, and patient satisfaction with treatment. Furthermore, these improvements were sustained for at least 6 months after the programme completion, particularly for factors such as fatigue, depression, anxiety, and vitality.

This study shows that a mildly intensive programme of relatively short duration can help patients with FM, for whom there is no specific treatment. Substantial additional 
work is needed, with larger study groups and longer follow up periods, to examine further the underlying mechanisms for the improvements seen here. Such work may provide further insights into the crucial elements of these multidisciplinary programmes, as well as the minimum duration and intensity necessary to achieve sustained improvements.

\section{ACKNOWLEDGEMENTS}

We thank Professor T Perneger for methodological advice, Dr B Aylward and Dr F Balagué for comments on earlier drafts of this manuscript.

We are grateful to the members of the multidisciplinary team who contributed to the programme: JP Gallice (PT), S Hurlimann (OT), M Jung (MD), D Kupper (OT), Y Leuridan (PT), D Monnin (head of physical therapy services), C Oberson (PT), J Pineau (PT), M Samaniego (psychologist), M Terrien (MD), and S Stingelin (MD), and to Ms S Vicari for considerable work in administering the study and programme schedules. We also thank Professor A Schnider, Professor JP Assal, and Professor P Dayer for their support.

The study was supported by a grant from the Swiss National Foundation for Research, grant No 3200-056028.98

\section{Authors' affiliations}

C Cedraschi, E Rapiti, E Baumgartner, A Finckh, T L Vischer, Division of Rheumatology, Geneva University Hospital, 1211 Geneva, Switzerland J Desmeules, Division of Clinical Pharmacology and Toxicology, Geneva University Hospital, 1211 Geneva, Switzerland

P Cohen, Clinic of Re-education, Geneva University Hospital, 1211 Geneva, Switzerland

A F Allaz, Clinic of Internal Medicine for Rehabilitation, Geneva University Hospital, 1211 Geneva, Switzerland

\section{REFERENCES}

1 Wolfe F, Smythe HA, Yunus MB, Bennett RM, Bombardier C, Goldenberg DL, et al. The American College of Rheumatology 1990 criteria for the classification of fibromyalgia. Report of the multicenter criteria committee. Arthritis Rheum 1990;33:160-72.

2 Wolfe F, Ross K, Anderson J, Russell IJ. Aspects of fibromyalgia in the general population: sex, pain threshold, and fibromyalgia symptoms. J Rheumatol 1995;22:151-6.

3 Goldenberg DL. An overview of psychologic studies in fibromyalgia. J Rheumatol 1989:16:12-14.

4 Burckhardt CS, Clark SR, Bennett RM. Fibromyalgia and quality of life: a comparative analysis. J Rheumatol 1993;20:475-9.

5 Henriksson C, Gundmark I, Bengtsson A, Ek AC. Living with fibromyalgia. Consequences for everyday life. Clin J Pain 1992;8:138-44

6 Burckhardt CS, Bjelle A. Perceived control: a comparison of women with fibromyalgia, rheumatoid arthritis, and systemic lupus erythematosus using a Swedish version of the Rheumatology Attitudes Index. Scand J Rheumatol 1996;25:300-6.

7 Martinez JE, Ferraz MB, Sato El, Atra E. Fibromyalgia versus rheumatoid arthritis: a longitudinal comparison of the quality of life. J Rheumatol 1995;22:270-4

8 Sandstrom MJ, Keefe FJ. Self-management of fibromyalgia: the role of formal coping skills training and physical exercise training programs. Arthris Care Res 1998; 11:432-47.

9 Alarcon GS, Bradley LA. Advances in the treatment of fibromyalgia: current status and future directions. Am J Med Sci 1998;315:397-404.

10 Richards S, Cleare A. Treating fibromyalgia [editorial]. Rheumatology (Oxford) 2000:39:343-6.

11 Mengshoel AM, Forre O, Komnaes HB. Muscle strength and aerobic capacity in primary fibromyalgia. Clin Exp Rheumatol 1990;8:475-9.

12 Bennett RM, Clark S, Goldberg L, Nelson D, Bonafede RP, Porter J, et al. Aerobic fitness in the fibrositis syndrome: a controlled study of respiratory gas exchange and Xenon 133 clearance from exercising muscle. Arthritis Rheum 1989;32:454-60.

13 Burckhardt CS, Bjelle A. Education programmes for fibromyalgia patients: description and evaluation. Baillieres Clin Rheumatol 1994;8:935-55.
14 Clark SR. Prescribing exercise for fibromyalgia patients. Arthritis Care Res 1994;7:221-5

15 Burckhardt CS, Mannerkorpi K, Hedenberg L, Bjelle A. A randomized, controlled clinical trial of education and physical training for women with fibromyalgia. J Rheumatol 1994;21:714-20.

16 Bennett RM, Burckhardt CS, Clark SR, O'Reilly CA, Wiens AN, Campbell SM. Group treatment of fibromyalgia: a 6 month outpatient program. J Rheumatol 1996;23:521-8.

17 Verstappen FTJ, van Santen-Hoeuftt HMS, Bolwijn PH, van der Linden S, Kuipers $\mathrm{H}$. Effects of a group activity programme for fibromyalgia patients on physical fitness and well-being. J Musculoskeletal Pain 1997;5:17-28.

18 Norregaard J, Lykkegaard JJ, Mehlsen J, Danneskiold-Samsoe B. Exercise training in treatment of fibromyalgia. J Musculoskeletal Pain 1997;5:71-9.

19 Wigers SH, Stiles TC, Vogel PA. Effects of aerobic exercise vs. stress management treatment in fibromyalgia. A 4.5 year prospective study. Scand J Rheumatol 1996;25:77-86.

20 Dupuy HJ. The Psychological General Well Being (PGWB) index. In: Wengger NK, Mattson ME, Furberg CD, Elison J, eds. Assessment of quality of life in clinical trials of cardiovascular therapies. Washington (DC): Le Jacq Publishing, 1984:770-83.

21 Deluze C, Bosia L, Zirbs A, Chantraine A, Vischer TL. Electroacupunture in fibromyalgia: results of a controlled trial. BMJ 1992;305:1249-52.

22 Baumgarmer E, Finckh A, Cedraschi C, Vischer TL. A 6 year prospective study of a cohort of fibromyalgia patients. Ann Rheum Dis 2002;61:644-6.

23 Perneger TV, Leplège A, Etter JF, Rougemont A. Validation of a Frenchlanguage version of the MOS 36-item short form health survey (SF-36) in young healthy adults. J Clin Epidemiol 1995:8:1051-60.

24 Burckhardt CS, Clark SR, Bennett RM. The Fibromyalgia Impact Questionnaire: development and validation. J Rheumatol 1991;18:728-33.

25 Lautenschläger J, Seglias J, Brückle W, Muller W. Comparisons of spontaneous pain and tenderness in patients with primary fibromyalgia. Clin Rheumatol 1991;10:168-74.

26 Finckh A, Morabia A, Deluze C, Vischer TL. Validation of questionnaire-based response criteria of treatment efficacy in the fibromyalgia syndrome. Arthritis Care Res 1998;11:116-23.

27 Potts MK, Silverman SL. The importance of aspects of treatment for fibromyalgia. Differences between patient and physician views. Arthritis Care Res 1990;3:11-18.

28 Gowans SE, deHueck A, Voss S, Richardson M. A randomized, controlled trial of exercise and education for individuals with fibromyalgia. Arthritis Care Res 1999;12:120-8.

29 Mannerkopi K, Nyberg B, Ahlmen M, Ekdahl C. Pool exercise combined with an education programme for patients with fibromyalgia syndrome. A prospective, randomized study. J Rheumatol 2000;27:2473-81.

30 Buskila D, Abu-Shakra M, Neumann L, Odes L, Shneider E, Flusser D, et al. Balneotherapy for fibromyalgia at the Dead Sea. Rheumatol Int 2001;20:105-8.

31 Jentoft ES, Kvalvik AG, Mengshoel AM. Effects of pool-based and land-based aerobic exercise on women with fibromyalgia/chronic widespread muscle pain. Arthritis Rheum 2001:45:42-7.

32 Karjalainen K, Malmivaara A, van Tulder $M$, Roine $R$, Jauhiainen $M$, Hurri $H$, et al. Multidisciplinary rehabilitation for fibromyalgia and musculoskeletal pain in working age adults [Cochrane review]. Cochrane Library. Issue 1. Oxford: Update Software, 2002

33 Pincus T, Wolfe F. An infrastructure of patient questionnaires at each rheumatology visit: improving efficiency and documenting care. J Rheumatol 2000;27:2727-30

34 Tugwell P, Bombardier C, Buchanan WW, Goldsmith CH, Grace E, Hanna B. The MACTAR Patient Preference Disability Questionnaire - an individualized functional priority approach for assessing improvement in physical disability in clinical trials in rheumatoid arthritis. J Rheumatol 1987;14:446-51.

35 Verhoeven AC, Boers M, van der Liden S. Validity of the MACTAR questionnaire as a functional index in a rheumatoid arthritis clinical trial. The McMaster Toronto Arthritis. J Rheumatol 2000;27:2801-9.

36 Naughton MJ, Wicklund I. A critical review of dimension-specific measures of health-related quality of life in cross-cultural research. Quality Life Res 1993;2:397-432

37 Barsky AJ, Borus JF. Functional somatic syndromes. Ann Intern Med 1999:130:910-21.

38 Katon W, Sullivan M, Walker E. Medical symptoms without identified pathology: relationship to psychiatric disorders, childhood and adult trauma, and personality traits. Ann Intern Med 2001;134:917-25.

39 Kalauokalani D, Cherkin DC, Sherman KJ, Koepsell TD, Deyo RA. Lessons from a trial of acupuncture and massage for low back pain: patient expectations and treatment effects. Spine 2001;26:1418-24.

40 Earnshaw SM, MacGregor G, Dawson JK. Fibromyalgia-monotheories, monotherapies and reductionism. Rheumatology (Oxford) 2001;40:348-9. 